\title{
Activation of human neutrophils by Esenbeckia leiocarpa: comparison between the crude hydroalcoholic extract (CHE) and an alkaloid (Alk) fraction
}

\author{
Rafael de Liz ${ }^{1,3}$, Heros Horst ${ }^{2}$, Moacir Geraldo Pizzolatti ${ }^{2}$, Tânia Silvia Fröde ${ }^{3}$ and Denis Girard ${ }^{1,4^{*}}$
}

\begin{abstract}
Esenbeckia leiocarpa, a wide spread native Brazilian tree, was reported recently to possess anti-inflammatory effects in vivo, but the mechanisms involved are still not fully understood and its role in neutrophils is poorly documented. The aim of this study was to compare the effects of a crude hydroalcoholic extract (CHE) and an alkaloid-enriched (Alk) fraction obtained from Esenbeckia leiocarpa bark on human neutrophils by investigating the effect of each fraction alone or in a mixture with classical neutrophil agonists. CHE inhibited intracellular reactive oxygen species (ROS) production but increased the extracellular superoxide $\left(\mathrm{O}_{2}^{-}\right)$production, while Alk increased the former and also slightly increased $\mathrm{O}_{2}^{-}$production. We found that $\mathrm{CHE}$ and Alk also induced phagocytosis accompanied by Syk activation, adhesion and degranulation. However, neither CHE nor Alk potentiated the effect of classical neutrophil agonists, namely the cytokines GM-CSF for phagocytosis and TNF-a for adhesion or N-formyl-methionyl-leucylphenylalanine (fMLP) for degranulation. In addition, based on catalase treatment, CHE and Alk induced neutrophil apoptosis by a hydrogen peroxide $\left(\mathrm{H}_{2} \mathrm{O}_{2}\right)$-dependent mechanism. Since the elimination of apoptotic neutrophils by professional phagocytes is important for the resolution of inflammation, the ability of CHE and Alk to induce neutrophil apoptosis has to be considered as one possible mechanism associated with the anti-inflammatory activity of these fractions previously reported in vivo.
\end{abstract}

Keywords: Plant extracts, Esenbeckia leiocarpa, Inflammation, Neutrophils

\section{Background}

Esenbeckia genus (Rutaceae) comprises a variety of species which have been popularly used to treat malaria in the Brazilian Amazon region [1,2]. Despite its ethnopharmacological approach, other biologic effects have been attributed to Esenbeckia species, including anticholinesterasic [3], antimicrobial [4], and antiparasitic [5] properties. Esenbeckia leiocarpa is a wide spread native Brazilian tree popularly known as guarantã, goiabeira, or guarataia [3]. Recent studies carried out in our laboratory have shown that this herb exerts a potent anti-inflammatory effect,

\footnotetext{
* Correspondence: denis.girard@iaf.inrs.ca

'Laboratoire de recherche en inflammation et physiologie des granulocytes, Université du Québec, INRS-Institut Armand-Frappier, Laval, QC, Canada ${ }^{4}$ INRS-Institut Armand-Frappier, 531 boul. des Prairies, Laval, QC H7V 1B7 Canada

Full list of author information is available at the end of the article
}

including a decrease in leukocyte migration, exudate levels, and pro-inflammatory mediators in different in vivo models [6,7]. Several studies have singled out alkaloids as being the most abundant class of chemical compounds present in Esenbeckia leiocarpa [6-9]. Notwithstanding, these compounds are known for their anti-inflammatory activity. For instance, phenanthroindolizidine and septicine alkaloid have demonstrated in vitro anti-inflammatory properties, since they supressed nitric oxide production in RAW 264.7 cells stimulated with LPS and interferon- $\gamma$ (IFN- $\gamma$ ) [10]. Other alkaloids, such as dehydroevodiamine, evodiamine, and rutaecarpine were effective in reducing both phorbol 12-myristate 13-acetate (PMA)- and N-formyl-methionyl-leucyl-phenylalanine (fMLP)-induced reactive oxygen species (ROS) production in neutrophils [11]. In addition, recent studies have shown that the alkaloid 
berberine induces apoptosis of human rheumatoid arthritis fibroblast-like synoviocytes [12].

Polymorphonuclear neutrophils (PMNs) have an essential role in the inflammatory response, since they are the first line of host defense against foreign microorganisms [13]. Notwithstanding, they have been implicated in the pathogenesis of several inflammatory diseases, including rheumatoid arthritis [14], type 2 diabetes [15], and chronic obstructive pulmonary disease [16]. These cells are activated and recruited to inflammation sites, where they exert phagocytic activity against invading pathogens and release different pro-inflammatory cytokines and chemokines, such as tumour necrosis factoralpha (TNF- $\alpha$ ) and interleukin-8 (IL-8) [17], as well as a variety of antimicrobial agents, including cationic peptides, proteases, lactoferrin, myeloperoxidase (MPO), and reactive oxygen species (ROS) by the exocytosis of cytoplasmic granules [13]. The aim of the present study was to compare the effects exerted by the crude hydroalcoholic extract and by an alkaloid-enriched fraction obtained from Esenbeckia leiocarpa bark, upon different neutrophil functions. Our results are the first to show that alkaloids represent an important fraction containing molecules responsible for the effect of Esenbeckia leiocarpa on phagocytosis, adhesion, and degranulation of human neutrophils, but not on ROS production.

\section{Methods}

\section{Reagents}

Dimethyl sulfoxide (DMSO), phorbol 12-myrostate 13acetate (PMA), tumour necrosis factor-alpha (TNF- $\alpha$ ), Nformyl-methionyl-leucyl-phenylalanine (fMLP), and lipopolysaccharide (LPS) were purchased from Sigma-Aldrich (St. Louis, MO, USA). Granulocyte macrophage colonystimulating factor (GM-CSF) was purchased from Pepro Tech Inc. (Rocky Hill, NJ, USA). The monoclonal antibodies against CD35 (clone E11) and CD63 (clone H5C6) were purchased from BD PharMingen (San Diego, CA, USA). The anti-CD66b mAb (clone $80 \mathrm{H} 3$ ) was obtained from AbDSerotec (Raleigh, NC, USA). The Syk inhibitor II (catalog no.57472) was purchased from EMD Biosciences. Specific rabbit-anti-human phosphorylated Syk antibody was purchased from Cell Signaling Technology (Danvers, MA, USA). Specific mouse Ab anti-human Syk was purchased from Santa Cruz Biotechnology (Santa Cruz, CA, USA).

\section{Plant materials, preparation of crude hydroalcoholic extract and alkaloid fraction}

Various samples of bark from Esenbeckia leiocarpa were collected in Arenápolis, a town located in the state of Mato Grosso, Brazil. They were collected in August 2007 and were identified by Dr. Celice Alexandre, of the University of the State of Mato Grosso, Tangará da Serra, MT,
Brazil, where a voucher specimen (38639) was deposited. Dried Esenbeckia leiocarpa bark (9 kg) was macerated and extracted with $90 \% \mathrm{EtOH}(24 \mathrm{~h} \times 3)$ resulting in a crude hydroalcoholic extract (CHE) (290 g). Some of the CHE $(20 \mathrm{~g})$ was partitioned between EtOAc and $5 \% \mathrm{HCl}$ solution. The $\mathrm{pH}$ of the acidic water-soluble material was adjusted to $\mathrm{pH} 9-10$ with $10 \%$ ammonia solution and was then extracted with EtOAc to yield an alkaloid (Alk) fraction $(5 \mathrm{~g})[6,7]$. Based on preliminary results, CHE and Alk were used at concentrations of 500 and $100 \mu \mathrm{g} / \mathrm{mL}$, respectively; at these concentrations, cell necrosis never exceeded $5 \%$, as assessed by trypan blue exclusion assay, and close to $80 \%$ of cells were in apoptosis (data not shown).

\section{Neutrophil isolation}

Neutrophils were isolated from venous blood of healthy volunteers by dextran sedimentation, followed by centrifugation over Ficoll-Hypaque (Amersham Pharmacia Biotech Inc., Baie d'Urfé, Québec, Canada), as described previously [18]. Blood donations were obtained from informed and consenting individuals according to institutionally approved procedures. Cell viability was monitored by trypan blue exclusion and found to be consistently $>98 \%$. Cell purity (>98\%) was verified by cytology from cytocentrifuged preparations coloured by Hema-3 staining kit (Biochemical Sciences Inc., Swedesboro, NJ, USA). Cell viability was evaluated systematically before and after each treatment. Neutrophils were then resuspended $\left(10 \times 10^{6}\right.$ cells/mL in RPMI-HEPES medium ( $25 \mathrm{mM})$, supplemented with penicillin $(100 \mathrm{U} / \mathrm{mL}) /$ streptomycin $(100 \mu \mathrm{g} / \mathrm{mL}))$ for all experiments.

\section{Measurement of intracellular ROS production}

To determine the effects of CHE and Alk on intracellular levels of ROS, cells $\left(1 \times 10^{6}\right.$ cells $\left./ \mathrm{mL}\right)$ were incubated for 5,15 , or 30 min with either CHE $(500 \mu \mathrm{g} / \mathrm{mL})$ or Alk $(100 \mu \mathrm{g} / \mathrm{mL})$ in the presence or absence of phorbol 12-myristate 13-acetate (PMA). Intracellular levels of ROS were detected using the probe $2^{\prime}, 7^{\prime}$ dichlorofluorescein diacetate $\left(\mathrm{H}_{2} \mathrm{DCFDA}\right.$; Molecular Probes, Eugene, OR, USA), as per the manufacturer's recommendation. After stimulation, cells were washed with PBS and stained with non-fluorescent cell-permeable $\mathrm{H}_{2}$ DCFDA $(5 \mu \mathrm{g} / \mathrm{mL})$ for 15 min at $37^{\circ} \mathrm{C}$. The $\mathrm{H}_{2}$-dichlorofluorescein oxidizes rapidly to the highly fluorescent dichlorofluorescein by ROS. As a positive control, the fluorescence intensity of cells pre-treated with $\mathrm{H}_{2}$ DCFDA was measured in the presence of PMA $\left(10^{-7} \mathrm{M}\right)$.

\section{Phagocytosis of sheep erythrocytes}

Sheep red blood cells (SRBCs) were opsonized with a final 1/200 dilution of rabbit IgG anti-SRBC antibody (Sigma-Aldrich) by incubation for $45 \mathrm{~min}$ at $37^{\circ} \mathrm{C}$, as previously described $[19,20]$. PMNs $\left(4 \times 10^{6}\right.$ cells $/ \mathrm{mL}$ in RPMI 1640) were pre-treated $30 \mathrm{~min}$ with buffer (1\% 
DMSO), GM-CSF (65 ng/mL) (positive control), as well as with $\mathrm{CHE}(500 \mu \mathrm{g} / \mathrm{mL})$ or Alk $(100 \mu \mathrm{g} / \mathrm{mL})$, in the presence or absence of GM-CSF $(65 \mathrm{ng} / \mathrm{mL})$. Cells were also incubated in the presence or absence of two different Syk inhibitors, piceatannol $(30 \mu \mathrm{M})$ or Syk inhibitor II $(30 \mu \mathrm{M})$. PMNs were then incubated with $20 \times 10^{6}$ opsonized SRBCs for $45 \mathrm{~min}$ as described above. The samples were centrifuged at $200 \times g$ at $4^{\circ} \mathrm{C}$ for $10 \mathrm{~min}$. Supernatants were discarded, and non-ingested SRBCs were eliminated by performing osmotic shock on the pellets, by treating them with $300 \mu \mathrm{L} \mathrm{H}_{2} \mathrm{O}$ for $15 \mathrm{~s}$ followed immediately by the addition of $4.5 \mathrm{~mL}$ ice-cold PBS (PBS; $1 \times$ ). The samples were washed twice with icecold PBS, and the pellets were suspended to a final concentration of $4 \times 10^{6}$ cells $/ \mathrm{mL}$. Duplicate cytocentrifuged preparations were prepared in aliquots of $\sim 200 \mu \mathrm{L}$, stained with the Hema-3 staining kit (Biochemical Sciences Inc., Swedesboro, NJ, USA), and observed by cytology, essentially as previously documented [19,21]. Phagocytosis was measured as percentage of neutrophils ingesting at least one opsonized SRBC.

\section{Neutrophil adhesion assay}

The adhesion assay was performed essentially as previously documented [22]. The human epithelial lung cell line A549 (ATCC) was grown in RPMI 1640 supplemented with 10\% FCS and antibiotics. Cell viability was systematically evaluated before and after each treatment, and mortality never exceeded 5\%. A549 cells were grown on glass coverslips; when at confluence, they were washed twice with PBS. PMNs were pre-treated for $30 \mathrm{~min}$ with buffer (DMSO 1\%) with or without either CHE $(500 \mu \mathrm{g} / \mathrm{mL})$ or Alk $(100 \mu \mathrm{g} / \mathrm{mL})$ in the presence or absence of tumour necrosis factor-alpha (TNF- $\alpha$ ) (10 ng/mL), and were labelled for $30 \mathrm{~min}$ with $5 \mu \mathrm{M}$ calceinAM (Molecular Probes, Eugene, OR, USA), according to the manufacturer's recommendation. After incubation, $500 \mu \mathrm{L}$ of neutrophil suspension $\left(10 \times 10^{6}\right.$ cells $\left./ \mathrm{mL}\right)$ was added to each well of a 12-well plate containing confluent A549 cells on a coverslip for $30 \mathrm{~min}$. After the incubation, coverslips were extensively washed and mounted on a glass slide. The number of adherent PMNs was calculated by counting the number of fluorescent cells from five randomly selected high-power fields (400x) observed with a photomicroscope Leica equipped with an ebq $100 \mathrm{dc}$ epifluorescent condenser.

\section{Degranulation of human neutrophils}

Cell surface expression of CD35, CD63, and CD66b was monitored for assessing degranulation of secretory, azurophilic, and specific granules, respectively, by flow cytometry, as previously described [23,24]. Briefly, non-specific binding of the antibodies was prevented by incubating the cells with $\mathrm{PBS}+20 \%$ decomplemented autologous serum for $30 \mathrm{~min}$ on ice. After several washes with PBS, primary antibodies or an IgG1 isotype control antibody were added at a concentration of $1 \mu \mathrm{g} / \mathrm{mL}$ in PBS for $30 \mathrm{~min}$ on ice. Cells were washed three times in PBS and incubated with $1 \mu \mathrm{g} / \mathrm{mL}$ FITC-conjugated goat anti-mouse IgG antibody for $30 \mathrm{~min}$ on ice. After three washes, cells were resuspended in PBS, and analysis was performed with a FACScan (BD Biosciences, San Jose, CA, USA).

\section{Zymography assay}

Neutrophils $\left(1 \times 10^{6}\right.$ cells $/ \mathrm{mL}$ in RPMI 1640 per condition) were pre-treated $30 \mathrm{~min}$ with buffer (1\% DMSO), with or without $\mathrm{CHE}(500 \mu \mathrm{g} / \mathrm{mL})$ or Alk $(100 \mu \mathrm{g} / \mathrm{mL})$, in the presence or absence of LPS $(1 \mu \mathrm{g} / \mathrm{mL})$, and then centrifuged at $13,000 \mathrm{rpm}$ for $10 \mathrm{~min}$ at $4^{\circ} \mathrm{C}$, and the pellets were discarded. The supernatants $(5 \mu \mathrm{L}$ corresponding to 50,000 cells) were mixed with a nonreducing buffer (40\% glycerol, Tris- $\mathrm{HCl} 1 \mathrm{M}, \mathrm{pH} 6.8$, SDS $8 \%$ ) and separated on $7.5 \%$ acrylamide gels containing $0.2 \%$ gelatin. Gels were washed twice for $30 \mathrm{~min}$ with 2.5\% Triton $\mathrm{X}-100$ and incubated overnight in digestion buffer (Tris-HCl 50 mM, pH 7.4, NaCl 150 mM, $\mathrm{CaCl}_{2}$ $5 \mathrm{mM}$ ). Gels were stained with Coomassie blue $0.1 \%$ and then destained.

\section{Assessment of neutrophils apoptosis by cytology}

Assessment of neutrophil apoptosis was performed essentially as previously described [25]. Briefly, freshly isolated human neutrophils $\left(10 \times 10^{6}\right.$ cells/mL in RPMI 1640 supplemented with $10 \%$ autologous serum) were incubated for $24 \mathrm{~h}$ in the presence (+) or absence (-) of CHE, Alk, with or without catalase. Cytocentrifuged preparations of neutrophils were performed with a Cyto-tek centrifuge (Miles Scientific, Elkart, IN, USA), as previously described and then were stained with the Hema-3 staining kit, as per the manufacturer's protocol. Cells were examined by light microscopy at a final magnification of $400 \mathrm{X}$ and apoptotic neutrophils were defined as cells containing one or more characteristically dark-stained pyknotic nuclei. Results were expressed as percentage of cells in apoptosis.

\section{Western blot analysis}

Neutrophils $\left(10 \times 10^{6}\right.$ cells/mL in RPMI-HEPES $(25 \mathrm{mM})$, penicillin $(100 \mathrm{U} / \mathrm{mL}) /$ streptomycin $(100 \mu \mathrm{g} / \mathrm{mL}))$ were stimulated with GM-CSF (65 ng/mL), CHE $(500 \mu \mathrm{g} / \mathrm{mL}$, Alk $\left(100 \mu \mathrm{g} / \mathrm{mL}\right.$ ), or buffer (DMSO $1 \%$ ) for $30 \mathrm{~min}$ at $37^{\circ} \mathrm{C}$. At the end of the incubation period, the cells were lysed in $4 \mathrm{x}$ Laemmli's sample buffer $(0.25 \mathrm{M}$ Tris- $\mathrm{HCl}, \mathrm{pH} 6.8,8 \%$ SDS, $40 \%$ glycerol, and $20 \% 2 \beta-\mathrm{ME}$ ), and aliquots corresponding to $1 \times 10^{6}$ cells were loaded onto $10 \%$ SDS-PAGE and transferred to nitrocellulose membranes (Amersham Pharmacia Bio-tech Inc., Baie d'Urfé, Que, Canada). Nonspecific sites were blocked with $3 \%$ bovine serum albumin (BSA) in TBS-Tween (25 mMTris- $\mathrm{HCl}, \mathrm{pH} 7.8,190$ $\mathrm{mMNaCl}, 0.15 \%$ Tween-20), and blots were incubated with antibodies as previously described [19]. Monoclonal rabbit 
anti-human phosphorylated Syk antibody (1:1000; Danvers, MA, USA) and HRP-goat anti-rabbit $(1: 15,000)$ were used. Membranes were stripped for $30 \mathrm{~min}$ at $55^{\circ} \mathrm{C}$ with stripping buffer (100 mM 2-ME, 2\% SDS, $62.5 \mathrm{mM}$ Tris, pH 6.7), washed, and reprobed with an specific mouse $\mathrm{Ab}$ antihuman Syk (1:1000; Santa Cruz, CA, USA) followed by a HRP-conjugated goat anti-mouse IgG + IgM (1:20,000; Jackson ImmunoResearch Laboratories, Inc.). Syk protein expression was revealed with ECL as per manufacturer's instructions.

\section{Superoxide production}

$\mathrm{O}_{2}^{-}$production was performed by colorimetric assay (reduction of cytochrome c), as previously published ${ }^{25}$. Briefly, neutrophils $\left(1 \times 10^{6}\right.$ cells $/ \mathrm{mL}$ in Hank's balanced salt solution (HBSS) supplemented with $1.6 \mathrm{M} \mathrm{CaCl}_{2}$ ) were incubated with $130 \mu$ cytochrome c (SigmaAldrich) for $5 \mathrm{~min}$ at $37^{\circ} \mathrm{C}$ in the presence $(+)$ or absence (-) of PMA, CHE or Alk. The absorbance of cytochrome c was monitored at $550 \mathrm{~nm}$ and the number of $\mathrm{O}_{2}^{-}$anions produced was calculated as previously published [25] using an extinction coefficient of 21.1.

\section{Statistical analysis}

Experimental data were expressed as mean \pm SEM. Significant differences between groups were determined by Student's $t$ test, when necessary, or two-way-analysis of variance (two-way-ANOVA), and then performed using GraphPad Prism, Version 5.01. Differences were considered statistically significant as follows: *, $P<0.05$ versus Ctrl or appropriated diluent.

\section{Results and discussion}

CHE is an inhibitor and Alk an inducer of ROS production in human neutrophils

As illustrated in Figure 1, CHE rapidly and significantly decreased the basal level of ROS production observed after 5 min of treatment. This decrease persisted for up to $30 \mathrm{~min}$, as assessed by flow cytometry with the $\mathrm{H}_{2}$ DCFDA fluorescent probe. Unlike CHE, Alk did not significantly decrease basal ROS production but, rather, induced it, although not significantly, after $30 \mathrm{~min}$ of incubation. ROS production was also determined in PMAinduced PMNs and both CHE and Alk caused significant decreases in ROS production.

Modulatory activity of CHE and Alk on the ability of PMNs to exert phagocytosis, adhesion and degranulation

Given that CHE and Alk can modulate a rapid response such as ROS production in human PMNs, we then determined whether or not one or both fraction(s) could modulate phagocytosis, adhesion and degranulation, three major functions of PMNs important for host defense that occurs relatively rapidly. Therefore, we

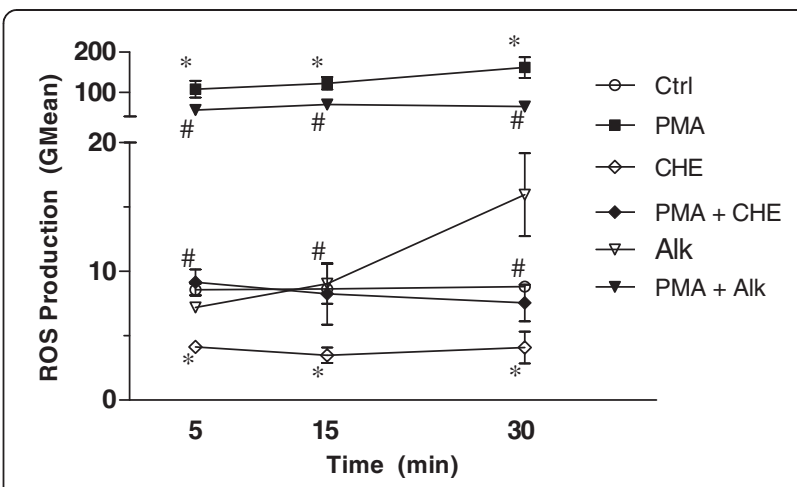

Figure 1 Effect of CHE and Alk on intracellular ROS production in human neutrophils. Freshly isolated human PMNs $\left(1 \times 10^{6}\right.$ cells $\left./ \mathrm{mL}\right)$ were incubated with diluent (1\% DMSO in HBSS, Ctrl), the positive control, PMA, CHE $(500 \mu \mathrm{g} / \mathrm{mL})$, Alk (100 $\mu \mathrm{g} / \mathrm{mL})$, PMA + CHE or PMA + Alk for 5, 15 or 30 min and intracellular ROS production was assessed by flow cytometry as described in Materials. Results are means $\pm \operatorname{SEM}(n=4)$. * $p<0.05$ vs $C$ trl; $\#, p<0.05$ vs PMA by student $-t$ test.

investigated the potential modulatory activity of $\mathrm{CHE}$ and Alk on these responses. As illustrated in Figure 2A, CHE and Alk significantly enhanced Fc-mediated phagocytosis of opsonized red blood cells $(61.7 \pm 3.2 \%$ and $73.0 \pm 4.6 \%$, respectively $(n=4))$ when compared to untreated cells $(43.0 \pm 5.6 \%)$, but did not potentiate the effect of the cytokine GM-CSF. In addition, this figure shows that the ability of either CHE or Alk to enhance phagocytosis was reversed by a Syk-selective inhibitor, indicating that both fractions enhanced phagocytosis by a Syk-dependent mechanism. To further elucidate this, we then demonstrated that Syk was activated in response to CHE or Alk, as evidenced by its increased level of phosphorylation (Figure 2B). CHE markedly increased the adhesion of PMNs on human epithelial A549 cells (ratio of $5.8 \pm 0.8, \mathrm{n}=3$ ); (Figure 3) this increased adhesion was even greater than that of the potent cytokine TNF- $\alpha(3.5 \pm 0.9)$ used as a positive control in this assay [22]. However, when PMNs were treated simultaneously with $\mathrm{CHE}$ and TNF- $\alpha$, the resulting ratio was $4.8 \pm 0.3$, which indicated an effect intermediate between that produced by either CHE or TNF- $\alpha$ only. Alk also increased the adhesion of PMNs but to a lesser extent than CHE $(2.4 \pm 0.1)$, but when mixed with TNF- $\alpha$, the result was similar to that of PMNs treated with TNF- $\alpha$ only $(3.3 \pm 1.0)$. We then evaluated the ability of CHE and Alk to modulate degranulation in neutrophils as assessed by flow cytometry, by monitoring cell surface expression of three important molecules known to be present in the different types of granule: CD63 (azurophilic granules), CD66b (specific and gelatinase granules) and CD35 (secretory granules) [24,26]. As illustrated in Figure 4A, CHE and Alk induced, with the same potency, the degranulation of secretory granules, as evidenced by 

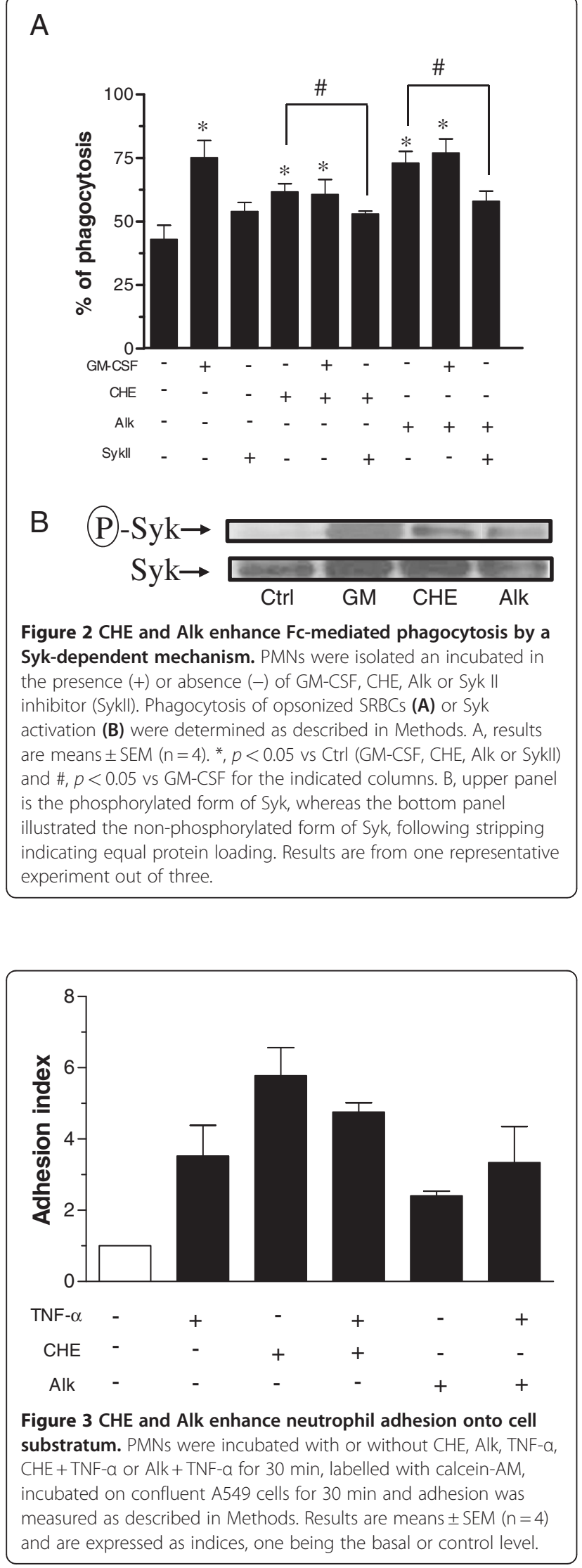

the increased cell surface expression of CD35, although to a lesser extent than fMLP, used as positive control. The cell surface expression of CD35 was not significantly modulated when cells were treated with CHE + fMLP and Alk + fMLP, when compared with fMLP only. CHE and Alk increased cell surface expression of CD66b but, unlike for CD35, when CHE or Alk was mixed with fMLP, the expression of CD66b was slightly decreased when compared to that produced by fMLP only (Figure 4B). Cells surface expression of CD63 remained stable in response to fMLP when compared to control cells, but was markedly, and significantly, increased by CHE and Alk (Figure 4C). In order to support CHE- or Alk-induced degranulation based on cell surface expression of a given marker, we then used the supernatants and performed zymography experiments. As illustrated in Figure 4D, CHE and Alk increased the activity of the matrix metalloproteinase-9 (MMP-9), also known as 92 $\mathrm{kDa}$ gelatinase (gelatinase B), and MMP-2 or $72 \mathrm{kDa}$ gelatinase (gelatinase A), as evidenced by an increased expression of the digested regions (bands) in the gel. Of note, gelatinase activity was more pronounced in response to Alk when compared to CHE. Also, Alk potentiated the activity of LPS, whereas CHE did not (or only slightly) promote such activity.

\section{Inhibition of $\mathrm{H}_{2} \mathrm{O}_{2}$ reverses the ability of $\mathrm{CHE}$ and Alk to} accelerate apoptosis

Neutrophils are known to undergo spontaneously in apoptosis (SA) [27] and many agents can accelerate or delay this biological process $[25,28,29]$. As illustrated in Figure 5 both CHE and Alk fractions accelerated SA. As expected, addition of catalase, an enzyme that degrades hydrogen peroxide $\left(\mathrm{H}_{2} \mathrm{O}_{2}\right)$, significantly delayed SA [25] and, also prevented the ability of CHE and Alk to accelerate SA. This suggested that $\mathrm{CHE}$ and Alk can also modulate a PMN function requiring several hours of incubation in vitro (24h).

CHE and Alk increase extracellular $\mathrm{O}_{2}^{-}$production in PMNs Because treatment with catalase inhibited the capacity of $\mathrm{CHE}$ and Alk to induce apoptosis, and since catalase used in the experiments is not cell permeable and degraded therefore $\mathrm{H}_{2} \mathrm{O}_{2}$ present in the extracellular medium, we then decided to verify whether extracellular ROS production was also increased in response to $\mathrm{CHE}$ and Alk. We measured the classic response of $\mathrm{O}_{2}^{-}$production, since $\mathrm{O}_{2}^{-}$anions are rapidly transformed into $\mathrm{H}_{2} \mathrm{O}_{2}$ via the action of the enzyme superoxide dismutase (SOD). As illustrated in Figure 6, after only $5 \mathrm{~min}$ of treatment, CHE significantly increased the rapid production of $\mathrm{O}_{2}^{-}$, whereas Alk did not, although a slight tendency towards increased production was noted. However, 


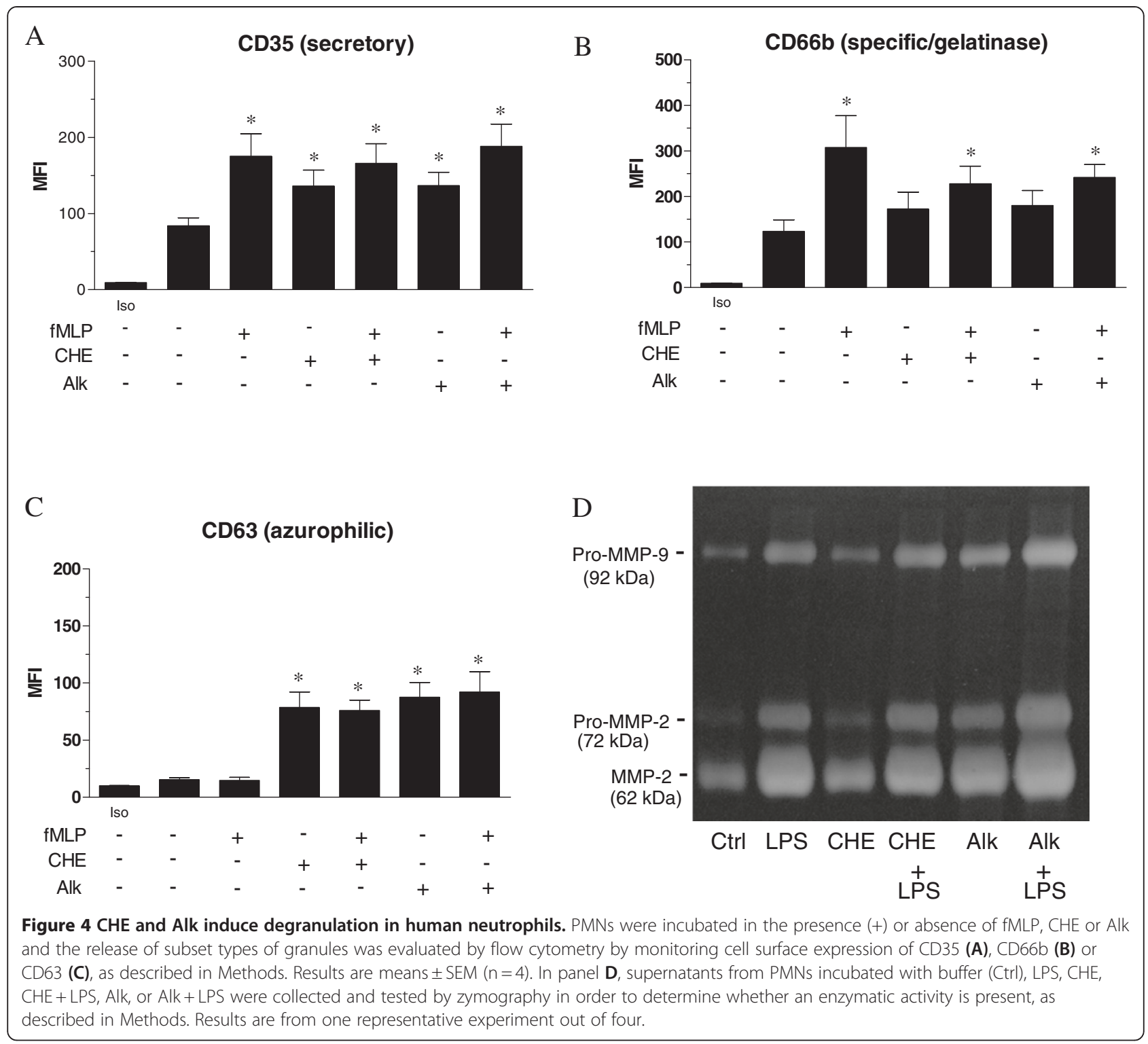

both $\mathrm{CHE}$ and Alk were found to significantly reduce the PMA-induced $\mathrm{O}_{2}^{-}$production.

\section{Discussion}

The discovery that Esenbeckia leiocarpa possesses some anti-inflammatory properties in vivo is recent $[6,7]$. The present work is the first study to investigate, in parallel, the role of both the crude hydroalcoholic extract $(\mathrm{CHE})$ and an alkaloid fraction (Alk), prepared from Esenbeckia leiocarpa bark in human PMNs, key players in inflammation. The various PMN functions were tested, not only in CHE- or in Alk-stimulated cells, but also, in cells treated with a combination of CHE or Alk and classical PMN agonists, namely, PMA for ROS production, GMCSF for phagocytosis, TNF- $\alpha$ for adhesion, and fMLP for degranulation. This strategy allowed us to study not only the direct effect of CHE or Alk on PMNs, but also when mixed with classical neutrophil agonists, a situation that is likely to occur in vivo where PMNs could be activated by several agents during inflammation [30]. From our results, it is clear that either CHE or Alk showed agonistic activities for human PMNs. This is consistent with a previous study indicating that E. Leiocarpa exerted an important anti-inflammatory effect in vivo in neutrophils, since a decrease of myeloperoxidase was noted [6], an enzyme considered as an important marker of PMN activation [31]. In general, for all tested functions, PMNs responded to both CHE and Alk in a similar fashion, except for ROS production; CHE inhibited intracellular ROS production but increased the extracellular $\mathrm{O}_{2}^{-}$production, whereas Alk (moderately) increased the former and also increased $\mathrm{O}_{2}^{-}$production, but not significantly. 


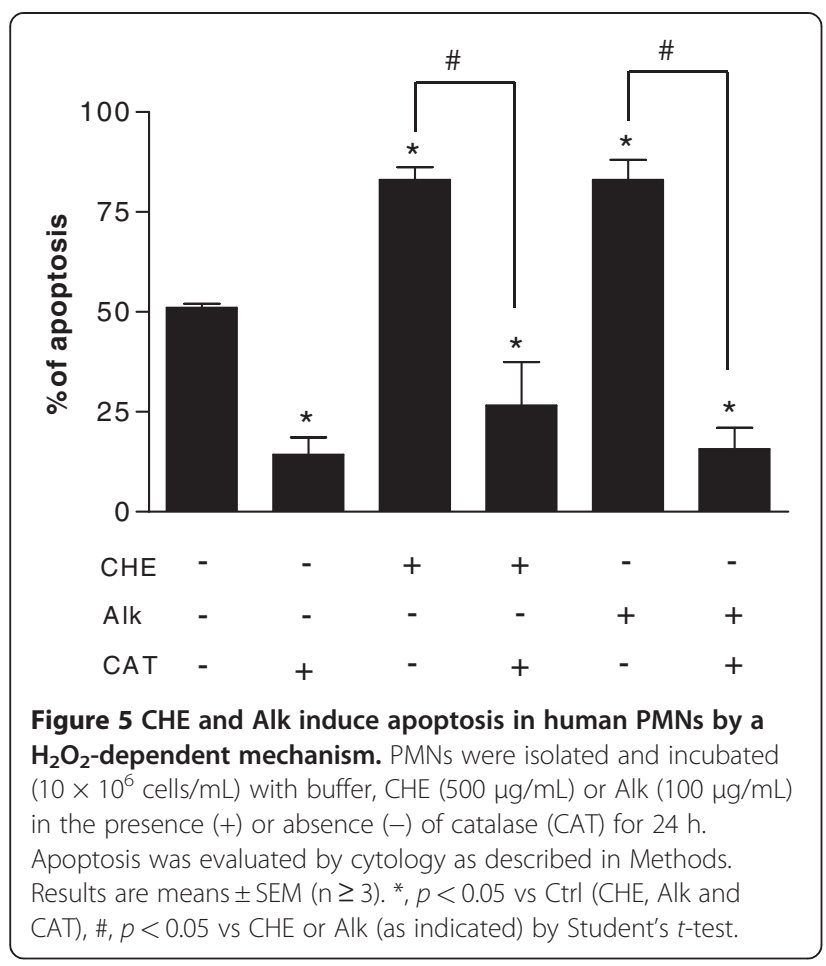

Of interest, both the crude extract and the alkaloidenriched fraction also demonstrated similar effects in vivo; they were found to inhibit leukocyte migration, exudate concentrations and proinflammatory mediators in carrageenan-induced inflammation in the murine air pouch model [6]. Therefore, Alk possesses some effects different than CHE in vitro and in vivo. It is difficult to explain with certainty why CHE decreased intracellular ROS production but increased extracellular $\mathrm{O}_{2}^{-}$production, while Alk

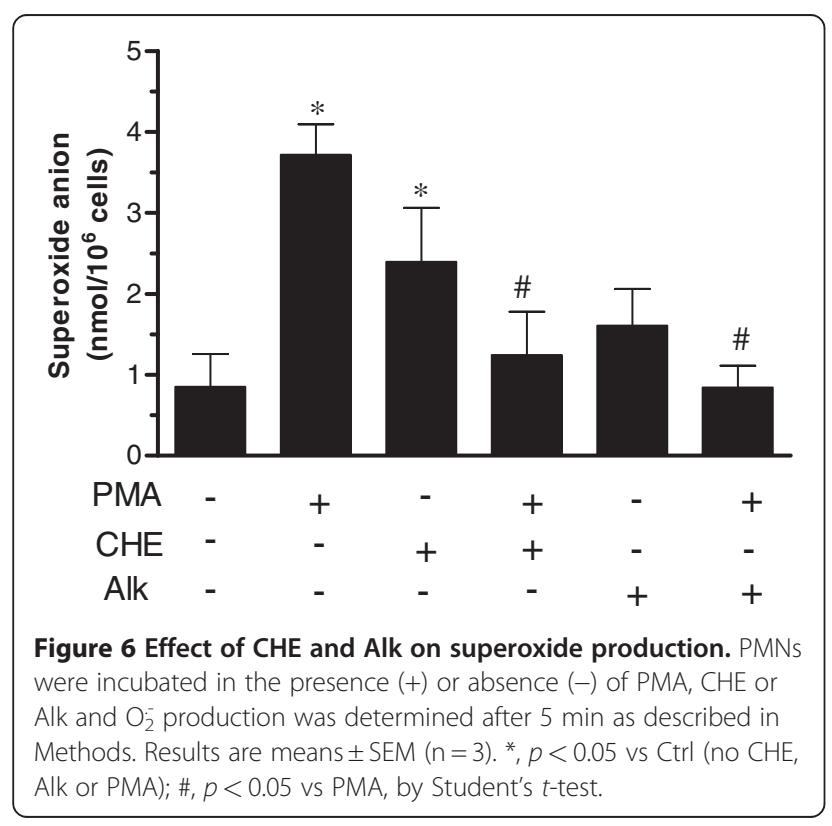

(slightly to moderately) increased both of these responses. One of the most probable reasons, although purely speculative at the moment, is the presence of other chemical compounds in the $\mathrm{CHE}$, apart from alkaloids that are equally present in the Alk. Of interest, CHE and Alk increased the PMN apoptotic rate to almost the same level after $24 \mathrm{~h}$ and this response was reversed by catalase. This effect suggests that even if CHE and Alk do not exert a similar effect upon general ROS production (intra and/or extracellular), similar levels of $\mathrm{H}_{2} \mathrm{O}_{2}$ are eventually present in the external medium of CHE- or Alk-stimulated PMNs. Interestingly, the role of $\mathrm{H}_{2} \mathrm{O}_{2}$ has been recently determined during neutrophilic inflammation in vivo during antigen-induced arthritis[32]. In this study, neutrophil recruitment was delayed in gp91 ${ }^{\text {phox }} \mathrm{KO}$ mice (that do not generate ROS, at least via NADPH activation) or after administration of catalase but was resolved after administration of $\mathrm{H}_{2} \mathrm{O}_{2}$ or superoxide dismutase [32]. Given the general involvement of ROS during PMN apoptosis, especially the role of extracellular $\mathrm{H}_{2} \mathrm{O}_{2}$ (since addition of catalase almost completely reversed spontaneous or agentinduced apoptosis [25]), the ability of CHE and Alk to produce extracellular $\mathrm{O}_{2}^{-}$, rapidly transformed into $\mathrm{H}_{2} \mathrm{O}_{2}$, is in accordance with the anti-inflammatory properties observed in vivo, since both CHE and Alk are proapoptotic for PMNs, an important event involved in the resolution of inflammation.

For the other functions tested, the difference observed between CHE and Alk was in terms of intensity of response. The most potent in vitro activity of CHE, when compared to Alk, is its ability to increase the adhesion of PMNs onto epithelial A549 cells. Whether CHE increased cell surface expression of some adhesion molecules, not induced by Alk, or if it acts by increasing such molecule expression with greater intensity than Alk in PMNs remains to be determined. The most potent in vitro activity of Alk when compared to CHE is its ability to strongly increase a gelatinase activity present in the supernatants, as assessed by zymography. Although this could not be directly related to the degranulation of gelatinase or specific granules (the cell surface expression of the CD66b marker is similar in CHE- or Alk-induced PMNs), it is important to specify that other enzymes also possess gelatinolytic activity [33] and this could, at least partially, explain why Alk and LPS had an increased gelatinolytic activity when compared to CHE. The ability of CHE and Alk to enhance Fc-mediated phagocytosis of opsonized SRBCs was, as other PMN agonists, including cytokines $[19,20]$, linked to Syk activation.

\section{Abbreviations}

CHE: Crude hydroalcoholic extract (CHE); Alk: Alkaloid Fraction Alk;

ROS: Reactive oxygen species; O2: Superoxide; $\mathrm{H}_{2} \mathrm{O}_{2}$ : Hydrogen peroxide; GM-CSF: Granulocyte macrophage colony-stimulating factor; PMA: Phorbol 12-myristate 13-acetate; fMLP: N-formyl-methionyl-leucyl-phenylalanine; 
PMNs: Polymorphonuclear neutrophils; TNF-a: Tumour necrosis factor-alpha; SA: Spontaneous apoptosis.

\section{Competing interest}

The authors have no competing interest.

\section{Acknowledgements}

This study was supported by the Natural Sciences and Engineering Research Council of Canada (NSERC). RL holds a doctoral award from the Brazilian government for training abroad. We thank Danielle Fontana Pereira for getting Esenbeckia leiocarpa bark and Mary Gregory for reading this manuscript.

\section{Author details}

'Laboratoire de recherche en inflammation et physiologie des granulocytes, Université du Québec, INRS-Institut Armand-Frappier, Laval, QC, Canada. ${ }^{2}$ Department of chemistry, Center of Physical and Mathematical Sciences, Federal University of Santa Catarina, Campus Universitário, Trindade, 88040970, Florianópolis, SC, Brazil. ${ }^{3}$ Department of Clinical Analyses, Center of Health Sciences, Federal University of Santa Catarina, Campus Universitário, Trindade, 88040-970, Florianópolis, SC, Brazil. ${ }^{4}$ INRS-Institut Armand-Frappier, 531 boul. des Prairies, Laval, QC H7V 1 B7 Canada.

\section{Authors' contributions}

$\mathrm{RL}$ carried out all experiments and participated in the data analysis and writing of the manuscript. $\mathrm{HH}$ and MGP were responsible for the plant extract preparations. TSF and DG, conceived of the study, participated in the design and coordination of the manuscript. All authors read and approved the final manuscript.

Received: 8 December 2011 Accepted: 28 May 2012

Published: 28 May 2012

\section{References}

1. Dolabela MF, Oliveira SG, Nascimento JM, Peres JM, Wagner H, Povoa MM, de Oliveira AB: In vitro antiplasmodial activity of extract and constituents from Esenbeckia febrifuga, a plant traditionally used to treat malaria in the Brazilian Amazon. Phytomedicine 2008, 15:367-372.

2. Carvalho LH, Brandao MG, Santos-Filho D, Lopes JL, Krettli AU: Antimalaria activity of crude extracts from Brazilian plants studied in vivo in Plasmodium berghei-infected mice and in vitro against Plasmodium falciparum in culture. Braz J Med Biol Res 1991, 24:1113-1123.

3. Cardoso-Lopes EM, Maier JA, da Silva MR, Regasini LO, Simote SY, Lopes NP, Pirani JR, Bolzani Vda S, Young MC: Alkaloids from stems of Esenbeckia leiocarpa Engl. (Rutaceae) as potential treatment for Alzheimer disease. Molecules 2010, 15:9205-9213.

4. Aguilar-Guadarrama AB, Rios MY: Geranyl N-dimethylallylanthranilate, a new compound from Esenbeckia yaaxhokob. Planta Med 2004, 70:85-86.

5. Napolitano HB, Silva M, Ellena J, Rodrigues BD, Almeida AL, Vieira PC, Oliva $\mathrm{G}$, Thiemann $\mathrm{OH}$ : Aurapten, a coumarin with growth inhibition against Leishmania major promastigotes. Braz J Med Biol Res 2004, 37:1847-1852.

6. Liz R, Pereira DF, Horst H, Dalmarco EM, Dalmarco JB, Simionatto EL, Pizzolatti MG, Girard D, Frode TS: Protected effect of Esenbeckia leiocarpa upon the inflammatory response induced by carrageenan in a murine air pouch model. Int Immunopharmacol 2011, 1:1.

7. Pozzatti P, dos Reis GO, Pereira DF, Heller M, Micke GA, Horst H, Pizzolatti MG, Frode TS: Esenbeckia leiocarpa Engl. inhibits inflammation in a carrageenan-induced murine model of pleurisy. J Pharm Pharmacol 2011, 63:1091-1102.

8. Nunes FM, Barros-Filho BA, de Oliveira MC, Andrade-Neto M, de Mattos MC, Mafezoli J, Pirani JR: $1 \mathrm{H}$ and 13C NMR spectra of 3,8dimethoxyfuro[3,2-g]coumarin and maculine from Esenbeckia grandiflora Martius (Rutaceae). Magn Reson Chem 2005, 43:864-866.

9. Nakatsu T, Johns T, Kubo I, Milton K, Sakai M, Chatani K, Saito K, Yamagiwa $Y$, Kamikawa T: Isolation, structure, and synthesis of novel 4-quinolinone alkaloids from Esenbeckia leiocarpa. J Nat Prod 1990, 53:1508-1513.

10. Lee YZ, Huang CW, Yang CW, Hsu HY, Kang IJ, Chao YS, Chen IS, Chang HY, Lee SJ: Isolation and Biological Activities of Phenanthroindolizidine and Septicine Alkaloids from the Formosan Tylophora ovata. Planta Med 2011, 4:4.
11. Ko HC, Wang YH, Liou KT, Chen CM, Chen CH, Wang WY, Chang S, Hou YC, Chen KT, Chen CF, Shen YC: Anti-inflammatory effects and mechanisms of the ethanol extract of Evodia rutaecarpa and its bioactive components on neutrophils and microglial cells. Eur J Pharmacol 2007, 555:211-217.

12. Wang $X H$, Jiang $S M$, Sun QW: Effects of berberine on human rheumatoid arthritis fibroblast-like synoviocytes. Exp Biol Med 2011 236:859-866.

13. Kumar V, Sharma A: Neutrophils: Cinderella of innate immune system. Int Immunopharmacol 2010, 10:1325-1334.

14. Cascao R, Rosario HS, Souto-Carneiro MM, Fonseca JE: Neutrophils in rheumatoid arthritis: More than simple final effectors. Autoimmun Rev 2010, 9:531-535.

15. Moreno-Navarrete JM, Fernandez-Real JM: Antimicrobial-sensing proteins in obesity and type 2 diabetes: the buffering efficiency hypothesis. Diabetes Care 2011, 34:S335-S341.

16. Mortaz E, Folkerts G, Nijkamp FP, Henricks PA: ATP and the pathogenesis of COPD. Eur J Pharmacol 2010, 638:1-4.

17. Tintinger GR, Steel HC, Theron AJ, Anderson R: Pharmacological control of neutrophil-mediated inflammation: strategies targeting calcium handling by activated polymorphonuclear leukocytes. Drug Des Devel Ther 2009, 2:95-104.

18. Girard D, Paquet ME, Paquin R, Beaulieu AD: Differential effects of interleukin-15 (IL-15) and IL-2 on human neutrophils: modulation of phagocytosis, cytoskeleton rearrangement, gene expression, and apoptosis by IL-15. Blood 1996, 88:3176-3184.

19. Ratthe C, Girard D: Interleukin-15 enhances human neutrophil phagocytosis by a Syk-dependent mechanism: importance of the IL-15Ralpha chain. J Leukoc Biol 2004, 76:162-168.

20. Ennaciri J, Girard D: IL-4R(alpha), a new member that associates with Syk kinase: implication in IL-4-induced human neutrophil functions. J Immunol 2009, 183:5261-5269.

21. Simard JC, Simon MM, Tessier PA, Girard D: Damage-associated molecular pattern S100A9 increases bactericidal activity of human neutrophils by enhancing phagocytosis. J Immunol 2011, 186:3622-3631.

22. Pelletier M, Girard D: Interleukin-15 increases neutrophil adhesion onto human respiratory epithelial A549 cells and attracts neutrophils in vivo. Clin Exp Immunol 2005, 141:315-325.

23. Simard JC, Girard D, Tessier PA: Induction of neutrophil degranulation by S100A9 via a MAPK-dependent mechanism. J Leukoc Biol 2010, 87:905914.

24. Jog NR, Rane MJ, Lominadze G, Luerman GC, Ward RA, McLeish KR: The actin cytoskeleton regulates exocytosis of all neutrophil granule subsets. Am J Physiol Cell Physiol 2007, 292:C1690-C1700.

25. Binet F, Cavalli H, Moisan E, Girard D: Arsenic trioxide (AT) is a novel human neutrophil pro-apoptotic agent: effects of catalase on ATinduced apoptosis, degradation of cytoskeletal proteins and de novo protein synthesis. Br J Haematol 2006, 132:349-358.

26. Binet F, Girard D: Novel human neutrophil agonistic properties of arsenic trioxide: involvement of p38 mitogen-activated protein kinase and/or c-jun NH2-terminal MAPK but not extracellular signalregulated kinases-1/2. J Leukoc Biol 2008,

27. Geering B, Simon HU: Peculiarities of cell death mechanisms in neutrophils. Cell Death Differ 2011, 18:1457-1469.

28. Akgul C, Moulding DA, Edwards SW: Molecular control of neutrophil apoptosis. FEBS Lett 2001, 487:318-322.

29. Bouchard A, Ratthe C, Girard D: Interleukin-15 delays human neutrophil apoptosis by intracellular events and not via extracellular factors: role of $\mathrm{Mcl}-1$ and decreased activity of caspase-3 and caspase-8. J Leukoc Biol 2004, 75:893-900.

30. Sheppard FR, Kelher MR, Moore EE, McLaughlin NJ, Banerjee A, Silliman CC: Structural organization of the neutrophil NADPH oxidase: phosphorylation and translocation during priming and activation. J Leukoc Biol 2005, 78:1025-1042.

31. Hampton MB, Kettle AJ, Winterbourn CC: Inside the neutrophil phagosome: oxidants, myeloperoxidase, and bacterial killing. Blood 1998, 92:3007-3017.

32. Lopes F, Coelho FM, Costa WV, Vieira EL, Sousa LP, Silva TA, Vieira LQ, Teixeira MM, Pinho V: Resolution of neutrophilic inflammation by $\mathrm{H}$ (2) $\mathrm{O}(2)$ in antigen-induced arthritis. Arthritis Rheum 2011 , 63:2651-2660. 
33. Descamps FJ, Martens E, Opdenakker G: Analysis of gelatinases in complex biological fluids and tissue extracts. Lab Invest 2002, 82:1607-1608.

doi:10.1186/1476-9255-9-19

Cite this article as: Liz et al:: Activation of human neutrophils by Esenbeckia leiocarpa: comparison between the crude hydroalcoholic extract (CHE) and an alkaloid

(Alk) fraction. Journal of Inflammation 2012 9:19.

\section{Submit your next manuscript to BioMed Central} and take full advantage of:

- Convenient online submission

- Thorough peer review

- No space constraints or color figure charges

- Immediate publication on acceptance

- Inclusion in PubMed, CAS, Scopus and Google Scholar

- Research which is freely available for redistribution 